\title{
METODE PENERJEMAHAN PHRASAL VERB DALAM DIALOG ANTARA PERAWAT DAN PASIEN
}

\author{
Herawati Br Bukit \\ Institut Kesehatan Deli Husada Deli Tua \\ e-mail :herawatihill02@gmail.com
}

\begin{abstract}
The main problem in translation techniques is whether the technique is translating literally or freely. The reason of this research was to observe an opportunity in the topic of phrasal verbs, to reveal the translation process of phrasal verbs in the nurse and patients dialogue into Bahasa Indonesia. Phrasal verb is also frequently used in their language. This research is used to analyze the phrasal verbs translation of Nurse with abroad patients' dialogues. Existing data are identified according to the theory of translation procedures from Vinay and Dalbernet (2000: 84-93). There are 7 translation methods that used in this research. There are two kinds of translation procedures, namely the Direct and Oblique methods; the direct method consists of three procedures, namely borrowing, calque and literal translation. Meanwhile, the oblique method consists of four procedures, namely transposition, modulation, equivalence, and adaptation. From the research conducted, 310 phrasal verbs were found which were translated through the Vinay and Dalbernet translation method, and the most dominant method used was modulation namely 150 phrasal verbs. It is used because there are many phrasal verbs when translated, variations in the form of a message are obtained by changing the perspective and involves replacing one class of words with another without changing the meaning of the message and also being applied in one language.
\end{abstract}

Keywords: Phrasal Verbs Translation, Nurses and Patients' Dialogue, Translation method

\section{PENDAHULUAN}

Masalah utama dalam teknik penerjamahan adalah tentang apakah tekhnik menerjemahkannya secara harfiah atau bebas. Terjemahan sebagai sarana untuk mentransfer pesan yang setara dari bahasa sumber (bsu) ke bahasa sasaran (bsa), sehingga komunikasi manusia yang sedang terjadi tetap terjaga. Terjemahan adalah mempelajari leksikon, struktur tata bahasa, komunikasi, situasi dan konteks budaya yang ada di bahasa sumber (bsu), kemudian menganalisisnya supaya dapat ditentukan artinya, kemudian merekonstruksi arti yang sepadan 
dengan menggunakan istilah dan struktur yang cocok dengan bahasa target (Larson, 1984:3).

Terjemahan adalah teks sasaran yang ditulis sebagai hasil pemahaman dari penerjemah terhadap source text. Akan tetapi, Venuti (2000: 126) menyatakan bahwa karena tidak ada dua bahasa yang identik, baik dalam arti yang diberikan pada simbol yang bersesuaian atau cara simbol tersebut disusun dalam frasa dan kalimat; masuk akal bahwa tidak ada korespondensi absolut antar bahasa.

Setiap pembicara langsung atau tidak langsung, sadar atau tidak sadar, tahu atau tidak tahu, mereka menggunakan phrasal verb pada saat berkomunikasi dalam bahasa Inggris. Phrasal verb adalah bagian yang sangat penting untuk mewarnai bahasa Inggris, mereka digunakan untuk memberi kehidupan dan kekayaan pada bahasa. Phrasal verb mengambil kata-kata yang ada, menggabungkannya dalam arti baru, dan membawa ekspresi yang baru.

Banyak orang berbicara
dengan menggunakan bahasa

Inggris sesuai dengan komponen, pola grammar dan strukturnya. Namun, phrasal verb dalam bahasa Inggris sering ditemukan, tapi jarang digunakan. Phrasal verb biasanya ditemukan pada saat orang melakukan proses penerjemahan. Phrasal verb adalah kombinasi dari kata kerja dan preposisi, kata kerja dan kata keterangan, atau kata kerja dengan kata keterangan dan kata depan, yang mana saja merupakan bagian dari sintaks kalimat, dan begitu juga unit semantik yang lengkap. Kalimat mungkin berisi objek langsung dan tidak langsung. Phrasal verb sangat sering ada dalam bahasa Inggris dan sering sekali memiliki arti yang berbeda dengan verba aslinya.

Berdasarkan karakteristiknya, orang kesulitan menerjemahkan phrasal verb. Dalam beberapa kasus, ketika diterjemahkan ke dalam bahasa lain, bisa jadi artinya berubah atau tidak ada artinya. Kasus ini mungkin terjadi dalam teks terjemahan percakapan antara perawat dan pasien. Dalam penelitian ini, penulis menganalisis phrasal verb yang ditemukan di percakapan yang terjadi antara perawat Indonesia dan pasien yang 
berasal dari luar negeri dalam kasus penelitian ini dalam percakapan bahasa inggris.

Sebagai pekerja sosial, perawat adalah orang-orang yang bekerja atas nama pengabdian masyarakat. Oleh karena itu, sebagai pengabdi masyarakat harus mampu melayani masyarakat dengan sepenuh hati. Jangan merasa terbebani sehingga bekerja dengan setengah hati atau lebih buruk lagi, pekerjaan yang ceroboh. Mulai dari pelayanan setengah hati hingga malpraktek.

Pada saat berkomunikasi
dengan pasien, sangatlah
dianjurkan bagi tenaga kesehatan
khususnya perawat untuk
menunjukkan ekspresi yang tepat,
apalagi pada saat melakukan
komunikasi dengan menggunakan
bahasa asing, dalam hal ini bahasa
Inggris yang merupakan bahasa
yang tidak sering dipakai oleh
perawat Indonesia pada saat
berkomunikasi.

Oleh karena itu, dialog antara perawat Indonesia dan pasien dari luar negeri merupakan penelitian besar yang harus didiskusikan, terutama untuk tata cara penerjemahan phrasal verb. Dalam hal ini penelitian dilaksanakan di Rumah Sakit Siloam yang menjadi Rumah Sakit Internasional yang berlokasi di Medan. Perawat yang bekerja di rumah sakit tersebut harus bisa berbahasa Inggris karena ada turis atau orang luar negeri yang datang ke rumah sakit untuk memeriksakan kesehatannya pada saat mereka berada di Medan. Dalam hal ini peneliti memilih dialog antara perawat dan pasien sebagai bahan penelitian.

Cullen - Hands (2000) menyatakan bahwa phrasal verb adalah frase dua kata pendek (atau kadang tiga kata) yang terdiri dari kata kerja, seperti get, give, make dan see, dan kata keterangan (partikel adverbial) atau kata depan, seperti in, off, out dan up. Karena phrasal verb merupakan bentuk idiom yang memiliki makna berbeda dengan penjumlahan bagian-bagiannya. Berdasarkan definisi di atas jelaslah bahwa dalam menerjemahkan suatu teks berarti mentransfer bahasa sumber (bsu) ke bahasa sasaran (bsa). Demikian juga yang terdapat dalam dialog antara perawat dan pasien. Ini tidak hanya mengenai phrasal verb dalam arti tetapi juga di tingkat tata bahasa. Contohnya: 
A. SL: Ok, I'll be right back with the thermometer TL: Ok, saya akan kembali setelah mengambil termometer

\section{SL: Ok, I am right back the ward \\ TL: Ok. Saya benar berada} dibelakang bangsal Mengingat kompleksitas semantik dan sintaksis phrasal verb dan kesulitan yang ditimbulkannya dalam proses penerjemahan, penerjemah menghadapi masalah dalam menerjemahkan phrasal verb dalam dialog Perawat dan pasien ke dalam bahasa Indonesia.

Pada preliminary data di atas bahwa kedua kalimat poin 1.a menggunakan phrasal verb "right back" yang diterjemahkan "kembali setelah mengambil" digabungkan dengan objek. Pada butir 1.a yang menggunakan satu verba mengacu Pada phrasal verb yang diterjemahkan ke dalam bahasa Indonesia yang memiliki dua verba "kembali dan mengambil" dan kasus lainnya yaitu butir 1.b menggunakan phrasal verb "right back" yang hanya menerjemahkan satu verba "benar berada dibelakang "dan juga disatukan oleh benda. Dari penjelasan dan sampel data di atas, ketidaksamaan dalam bentuk dan struktur kedua bahasa (perbedaan struktur tata bahasa dalam Bsu dan Bsa) dapat menyebabkan perubahan yang luar biasa dalam cara penyampaian informasi. Kata kerja majemuk bahasa Indonesia (poin 1.a kembali dan mengambil), yang memiliki pengertian yang sama dengan phrasal verb bahasa Inggris (right back) dan artinya terjemahannya sehingga sulit bagi penerjemah untuk menemukan makna dalam bahasa Indonesia dengan tetap mempertahankan makna dinamisnya. Sulit untuk mempertahankan korespondensi formal antara kedua teks tersebut. Jelas terlihat bahwa dalam situasi ini perbedaan antara kedua bahasa tersebut menyebabkan kerugian besar dalam proses penerjemahan. Berdasarkan penjelasan di atas, peneliti tertarik untuk mendalami bagaimana phrasal verbs yang memperkaya makna yang diterjemahkan dari Bsa ke dalam Bsu dalam dialog antara perawat and pasien untuk menemukan makna yang paling mendekati.

Ada dua macam prosedur penerjemahan yaitu metode Direct dan Oblique, metode direct terdiri dari tiga prosedur yaitu borrowing, 
calque dan literal translation. Sedangkan metode oblique terdiri dari empat prosedur yaitu transposition, modulation, equivalence, dan adaptation. Metode atau prosedur tampaknya tak terhitung banyaknya, tetapi dapat diringkas menjadi tujuh, masing-masing sesuai dengan tingkat kerumitan yang lebih tinggi. Dalam prakteknya, mereka dapat digunakan sendiri atau digabungkan dengan satu atau lebih dari yang lain (Vinay dan Dalbernet 2000:8493).

\section{Borrowing}

Borrowing adalah metode penerjemahan yang paling sederhana dari semua metode. Bahkan tidak akan ada gunanya diskusi dalam konteks ini jika penerjemah kadang-kadang tidak perlu menggunakannya untuk menciptakan efek gaya. Misalnya, untuk memperkenalkan cita rasa budaya bahasa sumber (Bsu) ke dalam terjemahan, istilah asing dapat digunakan. Zainurrahman (2009: 115) menyatakan bahwa meminjam mengacu pada kasus di mana sebuah kata atau ungkapan diambil dari Bsu dan digunakan dalam Bsa, tetapi dalam bentuk 'naturalisasi', yaitu dibuat agar sesuai dengan aturan tata bahasa atau pengucapan Bsa.

Contoh:

SL : She uses the microphone for singing

TL : Dia menggunakan microphone untuk bernyanyi

\section{Calque}

Ini adalah 'jenis peminjaman khusus' di mana ekspresi Bsu atau struktur ditafsirkan dalam terjemahan literal.

Contoh:

Lexical Calque :

SL : Good expression

TL : Ekspresi yang bagus

Structural Calque :

SL : Bali Post

TL : Bali Post

3. Literal translation

Ini adalah terjemahan 'kata per - kata', yang dideskripsikan sebagai prosedur terjemahan paling umum digunakan manusia antara bahasa dari keluarga dan budaya yang sama.

Newark(1988:69) menyatakan bahwa literal translation melampaui terjemahan satu-per-satu termasuk 
sebagai padanan literal, itu terutama berlaku untuk bahasa yang tidak memiliki artikel pasti dan / atau tidak terbatas. Sebagai proses pra-terjemahan, ini menunjukkan masalah yang harus diselesaikan.

Contoh:

SL : Agnez will go to Surabaya with a man tomorrow.

TL : Agnez akan pergi ke Surabaya dengan seorang anak laki-laki besok.

\section{Transposition}

Ini adalah prosedur perubahan dari satu bagian ucapan ke bagian lain tanpa merubah arti pesannya. Transposition juga dapat diterapkan dalam satu bahasa, selain menjadi prosedur terjemahan khusus. Ada dua jenis transposition yaitu obligatory transposition dan optional transposition.

Contoh :

SL : Marry

TL : Menikah dengan

Menikah dengan adalah kata kerja intransitif sementara menikah adalah kata kerja transitif.

\section{Modulation}

Modulation dalah suatu proses penerjemahan dimana variasi bentuk pesan diperoleh dengan adanya perubahan sudut pandang. Perubahan ini dapat dibenarkan jika, meskipun terjemahan literal, atau bahkan dialihkan, menghasilkan pengucapan yang benar secara tata bahasa, hal itu dianggap tidak sesuai, unidiomatic, atau canggung dalam Bsa. Zainurrahman (ibid: 117) modulasi sebagai prosedur penerjemahan terjadi ketika terjadi perubahan cara pandang yang disertai dengan perubahan leksikal dalam Bsa. Namun, prosedur ini sebaiknya dihindari kecuali diperlukan untuk kealamian terjemahan.

Contoh:

SL : I broke my leg

TL : Kaki saya patah

\section{Equivalence}

Ini mengacu pada kasus di mana bahasa menggambarkan kondisi yang sama dengan cara, gaya atau struktural yang berbeda. Ini sangat berguna dalam menerjemahkan idiom dan peribahasa. 
Contoh:

\section{$\mathrm{SL} \quad$ : It is raining cats and dogs \\ TL : Hujan yang sangat lebat \\ 7. Adaptation}

Adaptasi digunakan dalam kasus-kasus di mana tipe situasi yang dirujuk oleh pesan SL tidak diketahui dalam budaya TL. Dalam kasus seperti itu, penerjemah harus menciptakan situasi baru yang dapat dianggap setara. Dalam adaptasi, penerjemah bekerja mengubah isi dan bentuk Bsu dengan cara yang sesuai dengan kaidah bahasa dan budaya dalam masyarakat Bsa. Secara umum, prosedur ini digunakan sebagai cara yang efektif untuk menangani kata atau ekspres yang terikat budaya, metafora dan gambar dalam terjemahan. Artinya, penerjemah terpaksa menulis ulang SLT sesuai dengan karakteristik TLT (Zainurrahman, 2009: 117-118).

Contoh:

SL : She kissed her son on the mouth

TL : Dia memeluk putranya dengan lembut.

\section{METODE}

Penelitian ini menggunakan studi pustaka dan deskriptif kualitatif. Studi pustaka digunakan untuk mengetahui materi tentang phrasal verb dan buku yang digunakan untuk mencari penjelasan tentang teori-teori yang digunakan dalam penelitian. Selain itu, beberapa informasi juga ditemukan dari internet untuk mendukung atau melengkapi teori yang dikumpulkan. Metode deskriptif kualitatif digunakan untuk mendeskripsikan dan menjelaskan hasil temuan.

1. Kondensasi data

Kondensasi data bertujuan untuk mengolah data mentah yang muncul pada catatan lapangan tertulis untuk dianalisis. Prosesnya dapat berupa pemilihan, pemfokusan, penyederhanaan, pengabstrakan, dan transformasi. Dalam studi ini, langkah pertama dari kondensasi data meliputi proses pemilihan. Dalam proses ini klausul yang terdiri dari dialog antara perawat Indonesia dan pasien yang bersal dari luar negeri. Kemudian difokuskan pada klausa yang di dalamnya terdapat phrasal verbs beserta artinya agar benarbenar sesuai sebagai datanya. Dalam proses ini, huruf tebal digunakan sebagai tanda kata kerja phrasal verb dan artinya. Langkah selanjutnya adalah menyederhanakan. Dalam proses ini, jenis phrasal verb dan prosedur diberi beberapa kode agar lebih mudah diklasifikasikan pada setiap jenisnya. Peneliti menempatkannya ke dalam tabel-tabel yang sesuai dengan masing-masing jenisnya dengan mengkategorikan klausa yang berisi phrasal verb ke dalam 
jenis phrasal verb, prosedur yang digunakan dalam menerjemahkan phrasal verb. Setelah itu dilakukan abstraksi. Pada tahap ini peneliti mendeskripsikan analisis data dalam tabulasi dan bersama-sama dengan temuan penelitian dalam penelitian ini. Yang terakhir adalah transformasi.

\section{Display Data}

Ini adalah proses yang berkelanjutan, bukan hanya satu proses yang harus dilakukan di akhir pengumpulan data. Langkah ini, data diatur. Organisasi dibimbing untuk menjawab masalah penelitian dengan menggali dan mendeskripsikan ke dalam uraian yang detail. Dalam penelitian ini klausa yang berisi phrasal verb beserta artinya ditampilkan untuk mengelompokkan jenis dan prosedurnya.

3. Verifikasi and menyimpulkan

Analisis harus memungkinkan peneliti untuk mulai membuat kesimpulan tentang penelitian tersebut, kemudian kesimpulan awal ini kemudian dapat diverifikasi.

\section{HASIL DAN PEMBAHASAN}

Dari hasil penelitian ini ditemukan beberapa temuan bahwa:

1. Dalam dialog antara perawat Indonesia dan pasien yang berasal dari luar negeri ditemukan 310 phrasal verb yang terjadi pada saat mereka berkomunikasi.
2. Dari hasil analisis, peneliti menemukan bahwa pada saat penerjemahan phrasal verb versi bahasa Inggris terdapat tujuh metode penerjemahan menurut Vinay dan Dalbernet, namun dalam dialog ini peneliti hanya menemukan lima prosedur yang digunakan yaitu: Calque (50 phrasal verb), literal translation (30 phrasal verb), transposition (20 phrasal verb), modulation (115 phrasal verb) dan adaptation (95 phrasal verb)

3. Metode penerjemahan phrasal verb yang paling dominan digunakan dalam dialog antara perawat dan pasien adalah metode modulation. Itu digunakan karena ada banyak phrasal verb ketika diterjemahkan variasi bentuk pesan diperoleh dengan adanya perubahan sudut pandang dan melibatkan penggantian satu kelas kata dengan yang lain tanpa mengubah arti pesan dan juga diterapkan dalam satu bahasa.

\section{KESIMPULAN}

Dapat disimpulkan bahwa metode penerjemahan yang paling umum digunakan dalam menerjemahkan phrasal verb dalam dialog antara perawat dan pasien adalah metode modulation dengan jumlah 115 phrasal verb. Dan pada saat penerjemahan dialog tidak ada menggunakan metode borrowing dan calque. Selain itu, phrasal verb juga memiliki peran atau kegunaan yang sangat menarik untuk dipelajari, khususnya dalam 
percakapan antara perawat Indonesia dengan pasien yang berasal dari luar negeri dimana mereka saling berkomunikasi dengan mempercantik rangkaian kata di setiap ungkapan dan mampu menarik dan menjaga komunikasi yang baik supaya tidak terjadi kesalahpahaman diantara kedua belah pihak.

\section{DAFTAR PUSTAKA}

Acklam, Richard. 1992. Help with Phrasal Verbs. Oxford: The Bath Press.

Cullen, K \& Hands, P. $2000 . \quad A$ Guide to Phrasal Verbs. USA: Chambers Harrap Publishers.

Larson, L. Midred (1984). MeaningBased Translation: A Guide to Cross-Language Equivalence. U.K : University Press of America.

Newmark, Peter. 1981. Approaches to Translation. London: Oxford Press.
Newmark, Peter. 1988. A Text Book of Translation. London: Printice Hall.

Venuti, Lauren. 2000. The Translation Studies Reader. London: Routledge.

Zainurrahman. 2009. The Theories of Translation: From History to Procedures. Translation Directory.

Phrasal verb dictionary. Retrieved fromhttp://www.englishpage.c om/prepositions/phrasaldiction ary.html (March 2012) 